Article (refereed) - postprint

Johnson, Andrew C.; Jin, Xiaowei; Nakada, Norihide; Sumpter, John P.. 2020 Learning from the past and considering the future of chemicals in the environment

Copyright (C) 2020 The Authors, some rights reserved

This version is available at http://nora.nerc.ac.uk/id/eprint/527008/

Copyright and other rights for material on this site are retained by the rights owners. Users should read the terms and conditions of use of this material at https://nora.nerc.ac.uk/policies.html\#access

This is the author's version of the work. It is posted here by permission of the AAAS for personal use, not for redistribution. The definitive version was published in Science 367(6476): 384-387, 24 January 2020, DOI: 10.1126/science.aay6637. https://doi.org/10.1126/science.aay6637

This is the final manuscript version incorporating any revisions agreed during the peer review process. There may be differences between this and the publisher's version. You are advised to consult the publisher's version if you wish to cite from this article.

The definitive version is available at https://science.sciencemag.org 


\section{Learning from the past and considering the future of chemicals in the}

2 environment

3 Andrew C. Johnson ${ }^{1 *}$, Xiaowei Jin $^{2}$, Norihide Nakada ${ }^{3}$, John P. Sumpter ${ }^{4}$

41 Centre for Ecology and Hydrology, Benson Lane, Crowmarsh Gifford, Wallingford, 5 Oxfordshire, OX10 8BB, United Kingdom

62 China National Environment Monitoring Centre, Anwai Dayangfang No.8.Chaoyang

7 District, Beijing, China

83 Research Center for Environmental Quality Management, Kyoto University, 1-2

9 Yumihama, Otsu, Shiga, 520-0811, Japan

104 Institute for the Environment, Health and Societies, Brunel University London, Uxbridge,

11 Middlesex UB8 3PH, UK

*Corresponding author. Email: ajo@ceh.ac.uk

\section{ABSTRACT}

Knowledge of the hazards and associated risks from chemicals we discharge to the environment has grown considerably over the past 40 years. This improving situation stems from advances in our ability to measure chemicals at low environmental concentrations, recognition of a range of effects on organisms, and a worldwide growth in expertise. Environmental scientists and companies have learnt from the experiences of the past and in theory the next generation of chemicals will cause less acute toxicity, be less persistent and bioaccumulative. However, we still struggle to establish if the non-lethal effects associated with some modern chemicals and substances will have serious consequences for wildlife. It remains a challenge to obtain the resources appropriate to the magnitude of chemical challenges that lie ahead.

\section{Past and present examples}

Synthetic chemicals have provided dramatic improvements in food production and living standards (1). Although there are concerns over many hundreds of chemicals in the environment, there are only a few, albeit very important, examples of chemicals actually harming wildlife populations (Fig. 1). These examples showed us that hydrophobic (lipophilic) chemicals could both persist in the environment but also bioconcentrate, meaning the highest exposures would manifest themselves in long-lived top-predators. We also learnt that tests of acute toxicity on a necessarily limited range of laboratory-friendly species were 
not predictive for all species and effects so that more chronic tests on a wider range of organisms were needed. Knowledge gained from such disasters should make the use of chemicals increasingly safer. However, our past failures suggest we must be prepared for more surprises in future.

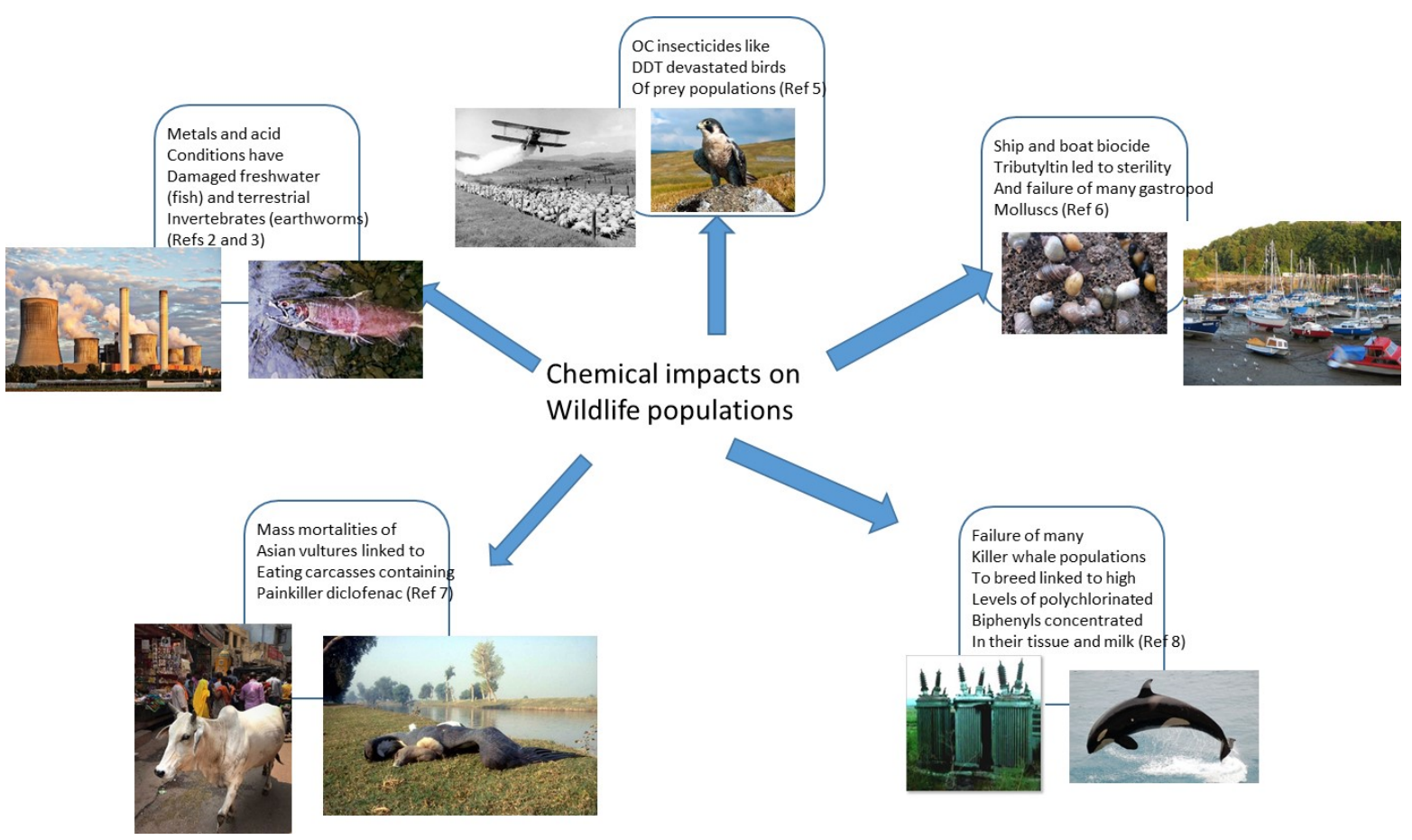

Figure 1. Classic examples of where chemicals actually have had or are having population level effects (2-6) (7) (8)

\section{The proportion of chemicals for which we have adequate environmental information}

The number of chemicals and substances on the market in places like the US and Europe, where data are accessible, is believed to be in the region of 75,000 to $140,000(9,10)$. Yet it is estimated we only have empirical data on persistence available for $0.2 \%$, bioconcentration data for $1 \%$ and aquatic toxicity for $11 \%$ of chemicals registered in the EU $(11,12)$ and there is a similar message from the US (9). In the absence of such hard information for the majority of chemicals, some help on the risks we face can come from computational predictive methods $(9,11)$. Nevertheless, the task is complicated by the formation of breakdown products in the environment for which we have less or no information. An additional challenge to our efforts to assess risk from these many chemicals entering the 
environment is the potential for mixture effects. This may lead to higher impacts on organisms than would have been predicted on the basis of individual chemical based risk assessments (13). Today’s research funding model tends to encourage widening and deepening studies on the current chemical, or group of chemicals, perceived to be of most concern, rather than supporting research on a higher proportion of the chemicals being discharged and considered potentially problematic (14).

\section{Chemical risks are not equal and nor is exposure}

Given the vast array of chemicals contaminating our natural environment, which are deserving of our greatest attention? For example, the risk of copper harming wildlife is reported to be 5-orders of magnitude higher than the drug atenolol (15) when comparing median exposure with median toxicity values for rivers in the United Kingdom. In other words, atenolol represented only $0.001 \%$ of the copper problem. In fact, metals dominated the top ten of 71 chemicals of concern studied in the United Kingdom (15) (Fig. 2) and are similarly highly ranked in China (16).

Chemical exposure from wastewater is not evenly spread around the world. This can be expressed as the extent to which the wastewater generated by an individual will be diluted by the natural river flow (17). Depending on landmass, population size and rainfall, some countries will face constant and widespread elevated exposure to chemicals in wastewater and others much less so (Fig. 3). 


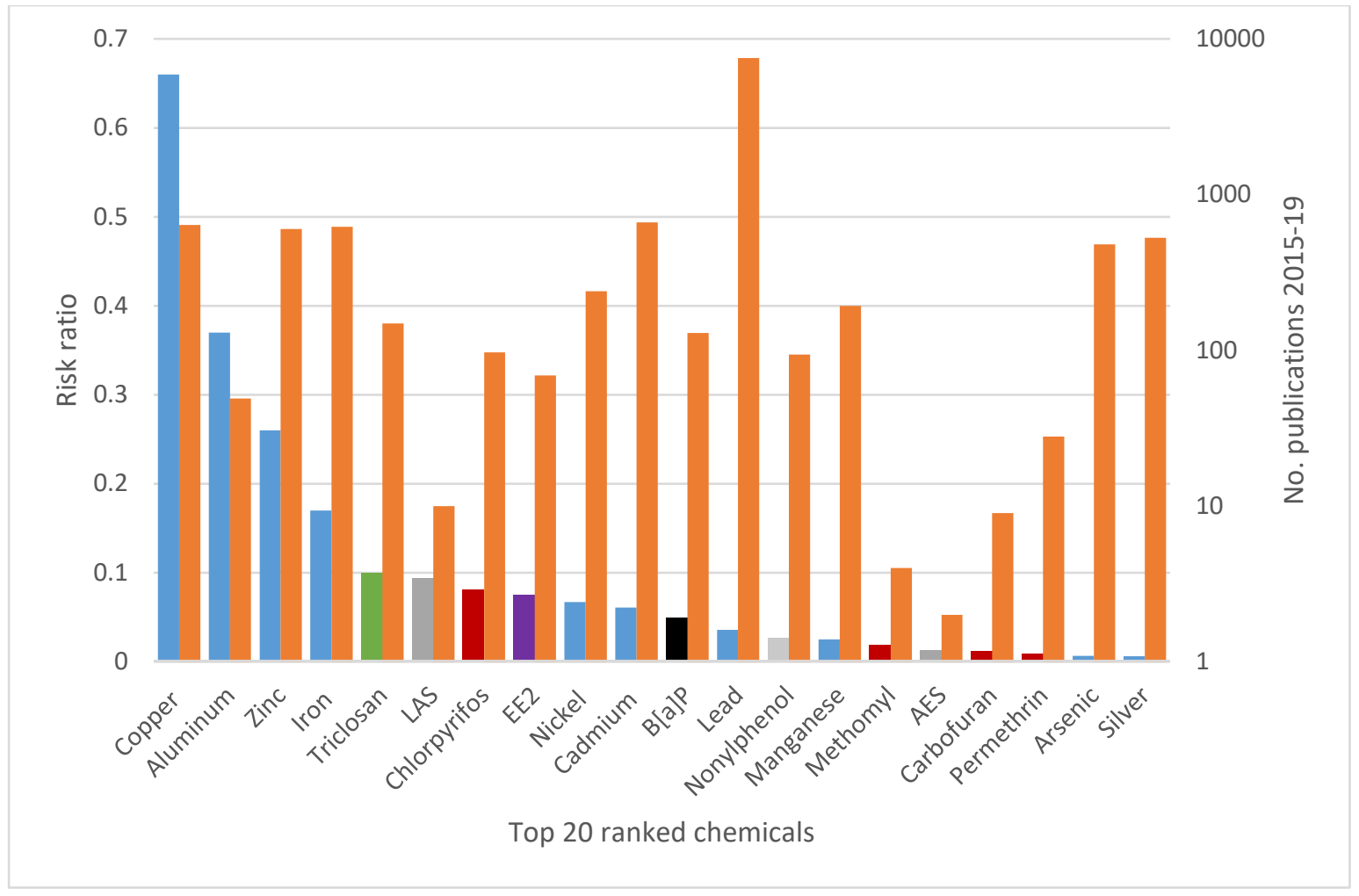

71

72 Figure 2 - The highest ranked 20 chemicals from a pool of 71 common chemicals found in

73 British Rivers ranked on the basis of the ratio of median river concentration vs the $5^{\text {th }}$ percentile of aquatic ecotoxicity data. Data from Johnson et al 2017 (15). Also shown, as orange bars, are the number of publications found on Web of Science in September 2019 under the search chemical AND environment AND risk for the period 2015-2019 for the same chemicals. Note LAS is linear alkylbenzene sulfonates, EE2 is ethinylestradiol, $\mathrm{B}[\mathrm{a}] \mathrm{P}$ is benzo[a]pyrene and AES is alcohol ethoxysulfates.

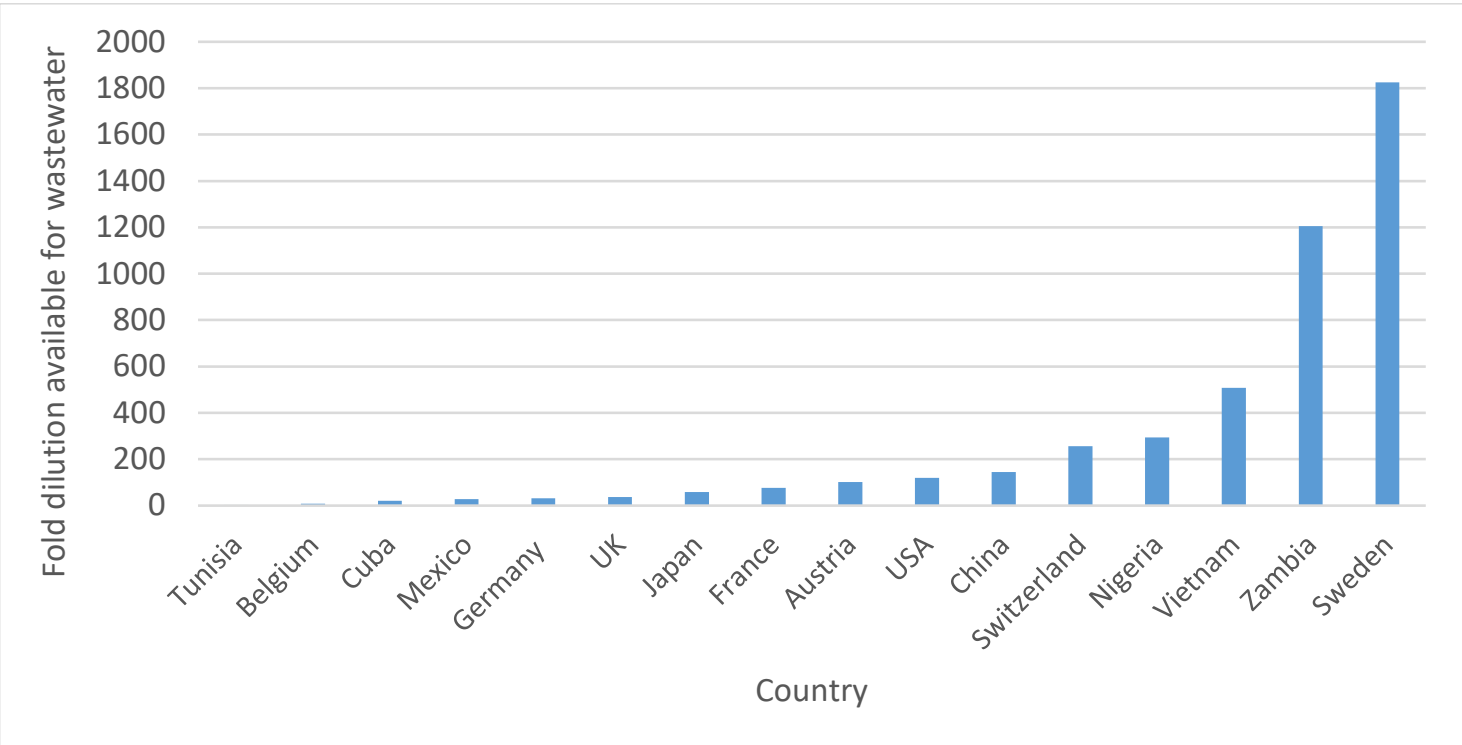


Figure 3. A few examples of the relative dilution of an individual's wastewater based on the median annual natural flow in their rivers for different countries. Data from (17)

\section{New chemicals and new places of concern}

There is an extraordinary diversity of services that modern society expects chemicals to supply. Examples include medicines, flame retardants and pesticides. We now recognise that the very properties that can make them work well for us can at the same time be deleterious for the wider environment. As medical knowledge grows, the expectation for new pharmaceutical-based treatments for diverse health conditions will continue. A current example is the clear incentive for drug companies to devise more effective compounds to treat a range of age-related conditions (18). Ethinylestradiol has been a very effective oralcontraceptive, but the combination of its potency and persistence made it an important contributor to endocrine disruption in wild fish downstream of wastewater effluent (19). We now know that if some of the new pharmaceuticals act as agonists or antagonists on the endocrine system, then the estrogen-based disruption story might be repeated with our fellow vertebrate, the fish (20). Following problems with the persistence and toxicity of polybrominated diphenyl ethers, the range of replacement candidate flame retardants are now much wider, including non-halogenated organic or metal compounds with phosphate groups, hydroxide or stannate groups (21). Concerns over pesticide mobility, non-target toxicity and persistence have drastically reduced the number of products for sale. The approaches of tomorrow are likely to be more precisely pest-targeted including RNA interference, pheromones and sterility. These new flame retardants and insecticides should be much safer, but we must be alert to surprises. Neonicotinoid use (an insect-specific post-synaptic agonist) had been considered sustainable, but now it is not (22).

The modern economy has been transformed by globalization. For chemicals this has meant the transfer of much chemical production to Asia (23), where chemical sales are $168 \%$ of the US and Europe combined (Fig. 4). However, in some cases weak regulation or uneven local enforcement has led to examples of severe pollution hotspots. Examples include atmospheric contamination with chlorofluorocarbons (CFCs) coming from the Shandong and Hebei provinces of China (24), gross perfluorooctanoic acid (PFOA) pollution from a vast Chinese manufacturing site (25) and antibiotics from a manufacturing plant in India (26). However, it must be recognised that successful management of industrial waste and indeed pollution is far from straightforward. It is one thing to set water quality targets, but these can only work 
where there is a clearly independent regulator taking consistent high quality measurements with an independent judiciary to apply to, both supported by local and national governments. The degree to which environmental protection is improved by centralisation or when it is devolved to local administrations is debatable (27). In the case of local governance in China, there is evidence for uneven application of regulations $(28,29)$. Protection is also boosted by a national commitment to transparency, in which the scrutiny by the public, environmental non-governmental organisations and journalists are accepted. This is not a given throughout the world $(30,31)$.

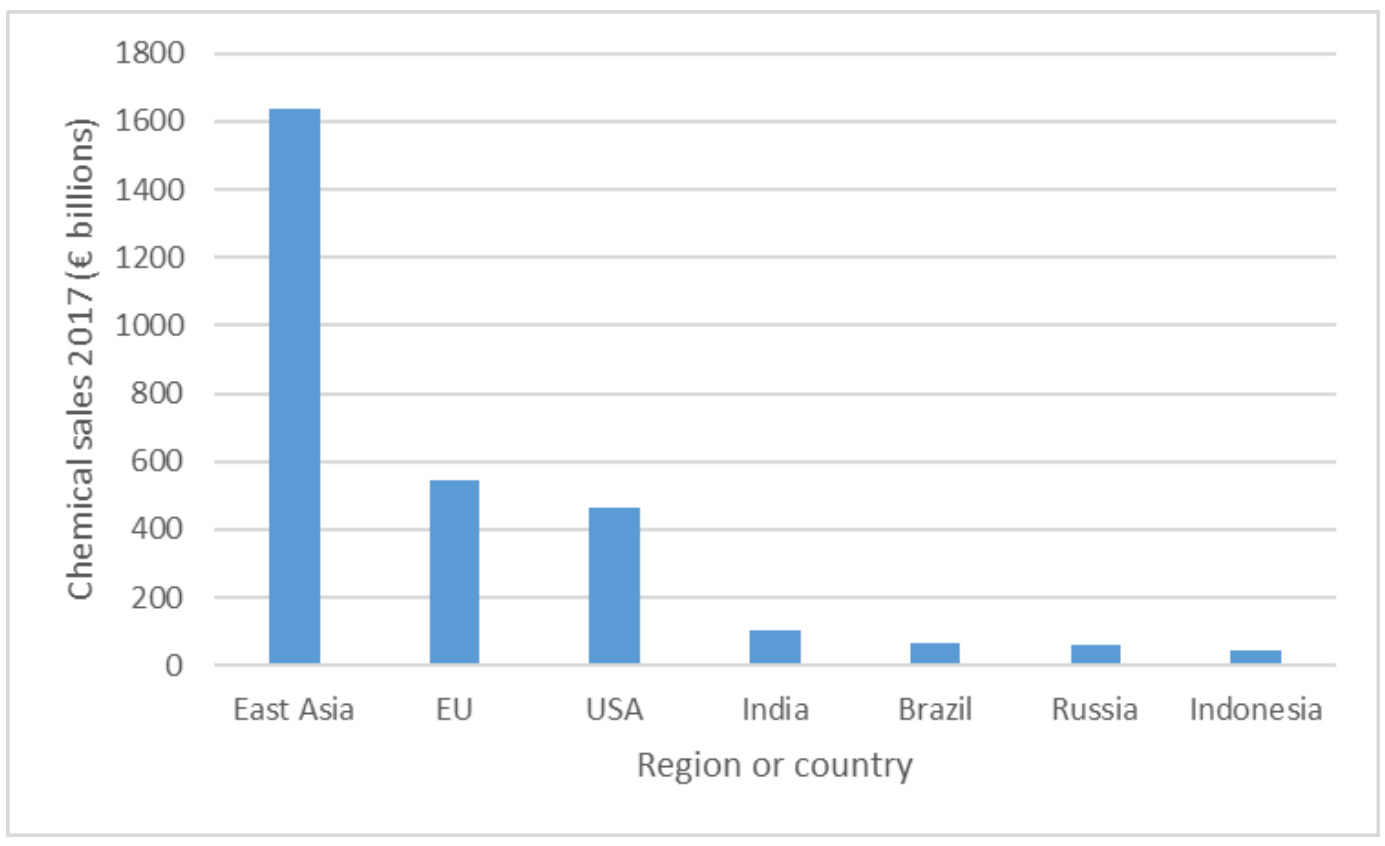

Figure 4. The level of chemical sales in 2017. East Asia includes China, Japan and South Korea (23)

\section{Reasons for optimism}

\section{Progress in regulation and management of chemicals in the environment}

Chemical regulations in the 1960s and 70s concentrated on remediating past pollution and controlling the emission of a limited number of pollutants. This became forward-looking so that new chemicals wishing to enter the market should conform to minimum human safety and environmental standards. Examples would be the "Toxic Substances Control Act” (TSCA) in 1976 (Public Law 94-469) in the US and Registration, Evaluation, Authorisation and Restriction of Chemicals (REACH) (EC 19072006) in the EU. Given the many chemicals 
that entered the market before these laws were enacted, a retrospective authorization process is trying to catch up. Whilst not perfect, the establishment of regulations like TSCA and REACH set an important precedent that the onus to demonstrate a chemical was safe for humans and the environment should lie with the manufacturer. The phrase in Europe is 'no data, no market’ (32).

\section{Analytical developments, knowledge of undesirable chemical characteristics and alternatives to animal testing}

Developments in analytical chemistry continue to drive down limits of detection. The opportunity is now also arising to search for and tentatively identify all the molecules present, known and unknown, with non-targeted screening methods (NTS) (33). Recent examples where NTS has opened a window include revealing the range of compounds found in urban runoff (34), to being able to fingerprint unusual pollution incidents and to identify the industrial premises responsible (35). A recent intriguing development is acquiring historic analytical raw data from previous studies for the retrospective analysis for "new" pollutants that were not originally targeted (36). These new approaches will help to make the environment more transparent with respect to chemical contaminants.

There is now much shared knowledge on the undesirability of properties such as hydrophobicity and persistence in chemicals that we intend to discharge to the environment. In the consumer goods industry, recognition of poor biodegradability has now led to replacement of branched alkylbenzene suphonates by linear forms, the replacement of long chain dialkyl quaternary surfactants by ester-based quaternaries, nonylphenol ethoxylates (also having toxic concerns) by alcohol ethoxylates, and the replacement of musk xylene by macrocyclic musks. Although not driven primarily by environmental concerns, an increasing proportion of new pharmaceuticals being registered are the so-called biologics. For example, 12 of the 30 new drugs registered for the German Market in 2016 noted by the German Pharma Association, and 75 of the recent top 200 selling retail drugs in the USA (37), are made from biological material such as proteins, genes, allergens and cells, which are considered not to pose the persistence issues of small synthetic molecules.

There is an understandable reluctance to submit the vast numbers of animals needed for laboratory toxicity tests for the many thousands' of chemicals that still need to be registered, and this has stimulated toxicity and exposure model developments (9). Computer models have 
been used to help predict which chemicals are going to be of greatest concern (in silico risk assessment); in other words those that will be persistent, bioaccumulative and toxic (PBT). In a survey of 95,000 chemicals, the model predicted that only 3 to 5\% were likely to be PBT (11).

\section{Better wastewater treatment and International chemical initiatives}

There are considerable benefits, not just to general water quality, but to chemicals reduction by moving from primary wastewater treatment (settling) to secondary treatment (biological) and increasing the biological treatment time in secondary treatment from simple methods like trickling filters to activated sludge $(38,39)$. The widespread adoption of the activated sludge process (ASP) in towns and cities around the world, with its biological treatment time of $8 \mathrm{~h}$ or more, has done a great deal to protect rivers from the worst consequences of high chemical exposures. In China, it is now reported that $94 \%$ of the urban population have wastewater treatment with $81 \%$ using advanced processes like ASP (40). Whilst not perfect, their introduction can significantly improve water quality and hence biodiversity when compared to more historic and less efficient treatment (38). It is within our power, if we wish it, to introduce stringent tertiary treatment, to eliminate all organics from effluent, and this is being applied in some parts of Switzerland (41)

Developed and many developing countries share many of the same chemical challenges and this is particularly true for many persistent pollutants which know no boundaries. Thus, it is encouraging to see international agreements on POPs (Stockholm Convention), mercury (Minamata Convention) hazardous waste disposal (Basel Convention), and certain hazardous chemicals and pesticides (Rotterdam Convention). Sensible advice on managing chemicals including legal, economic, technical and voluntary instruments including the adoption of safer alternatives is now available to all countries (42).

\section{Reasons for pessimism}

\section{Continuing uncertainty over the importance of non-lethal effects}

Once we move away from apical end-points (non-lethal or end-points which disrupt reproduction or growth), it remains a matter of speculation as to whether the response to a chemical seen in the laboratory really translates to harm to individuals or populations in the 
wild. The detailed mechanistic detection work of an adverse outcome pathway (AOP), in theory, predicts the harmful outcome of effects from the molecular level all the way up to that of the population (43). AOPs have confidently predicted population effects on fish from endocrine disrupters (44), and yet this has not been observed in the field (45). It is presently unclear if the development of AOPs will aid in the environmental risk assessment of chemicals. Can gene, protein or metabolite expression studies on their own, be predictive of actual impacts on wildlife populations or indeed food webs (46)?

\section{Data quality and the relevance of research topics}

It is now widely accepted that a significant proportion of published research is not reproducible, a situation sometimes called the 'reproducibility crisis' $(47,48)(49)$. Reasons include: perverse incentives on research scientists to publish 'exciting' research and a general lack of training of researchers (50). Two common problems are poor experimental design and bias (51). In ecotoxicology, many scientists conduct their research on animals not routinely used in regulatory tests, and which other researchers rarely utilise.

The focus of public concern over chemicals is unpredictable. This can lead to sudden demands for information which can overwhelm everything else. Inevitably, many fundable topics will have to be dropped in order to concentrate on an area of new concern. A dramatic growth area has been nanoparticles and the environment, which when searched under Web of Science reveals interest has grown from 36 papers/yr in 2000 to 4,200/yr in 2017. Yet many studies appear to show a modest relative risk, at least for common metal-based nanoparticles $(15,52)$. Another example might be bisphenol-A, an additive used in many plastic items, which has been shown to be a weak estrogen. Many hundreds of studies have been published on its presence and possible harm to the environment (WoS ${ }^{\mathrm{TM}}$ finds 630 papers when BPA, effect and environment are the search terms in September 2019). Yet the evidence that bisphenol-A is adversely affecting wildlife is essentially non-existent (53). On the other hand, we have many thyroid active, cardiovascular, antiepileptics and muscle relaxant drugs for which few if any studies have been carried out on their possible effects on aquatic wildlife.

It might surprise many people to learn that often the focus of research into chemicals in the environment is not necessarily linked to their relative risk. For the top 20 highest risk ranked chemicals in British rivers (Fig. 2) we found that publications related to their environmental 
risk varied between 7,531 for lead to only 2 for the anionic surfactant, alcohol ethoxysulfates in the period 2015-2019 (Fig. 2).

This area of science is prone to the 'bandwagon' effect, by which many papers only demonstrate what we knew already: did we need 250+ papers to tell us that ethinylestradiol poses a risk to fish? Everything we needed to know to protect the environment we knew from the first half a dozen papers. A current trend is this desire to search for more-and-more subtle 'effects', such as one or a few genes being tweaked a tad, when the consequences of those effects are completely unknown.

\section{Risk assessments are getting further behind and scientists tend to stay in their silos}

Thorough risk assessment is costly and can require decades of research. Given the range of species and number of end-points that could be examined, it seems certain we will never catch up using our traditional approaches (54). If this assertion is correct, then persevering with the present testing strategy does not seem appropriate. Ethical objections to the use of animals, particularly vertebrates, in tests are increasing, yet we continue to add more tests to the Organisation of Economic Cooperation and Development (OECD) battery of accepted (eco) toxicity tests. Re-thinking how the environmental risks of a chemical can be assessed, with a bigger role for predictive modelling of harmful properties, is ongoing, but regulators remain cautious about placing reliance on such information (55)

The study of chemicals in the environment appears to revolve largely around the two disciplines of ecotoxicology and environmental chemistry. It is common for ecotoxicologists in their publications to state that 'effects were observed at environmentally relevant concentrations' whilst environmental chemists for their part are often tempted to assert that their 'highest measured concentrations exceeded reported effect (toxic) concentrations' (56). Such statements imply there are problems out there, possibly very big ones. However, it is unclear, based on the evidence of ecotoxicology and environmental chemistry alone, whether we are exaggerating the dangers and so over-regulating or alternatively underestimating risks (such as been proposed from mixture effects) and so failing to protect (54). There is a $3^{\text {rd }}$ community of scientists, who in theory have much to offer in assessing chemical impacts on wildlife and these are ecologists. The presence of long-term wildlife, monitoring is vital for such research. But we still see surprisingly few examples of collaboration between 
ecologists, ecotoxicologists and environmental chemists. Ecologists have highlighted alarming declines in some wildlife $(57,58)$, and despite many confounding variables, longterm ecological data can be extremely compelling at establishing a link that can cut across competing arguments, such as with neonicotinoids and bees $(22,46)$. To determine the true harm of chemicals, these different scientists will need to collaborate closely (59).

\section{Conclusions}

Adapting to the immensely difficult societal and environmental challenges of tomorrow will undoubtedly require new chemicals and chemical solutions. The production of chemicals, their diversity and use around the world has never been greater. Our ability to manage the risks are finely balanced, with reasons to be both pessimistic and optimistic. Unfortunately, the sheer number of chemicals on the market, and presumably also entering the environment, are currently beyond our ability to assess the risks from them all. Although there are no guarantees, our past knowledge married to ‘in silico’ modelling of hazards are helpful in gauging relative risk. Provided we maintain long-term wildlife monitoring efforts, particularly in areas of land or water most exposed to chemicals, we may have some confidence that our use of chemicals is sustainable.

\section{References}

1. J. E. Casida, G. B. Quistad, Annu. Rev. Entomol. 43, 1-16 (1998).

2. C. A. Mebane, R. J. Eakins, B. G. Fraser, W. J. Adams, Elementa, 1-34 (2015).

3. D. J. Spurgeon, S. P. Hopkin, D. T. Jones, Environ. Pollut. 84, 123-130 (1994).

4. J. Herrmann et al., Ambio 22, 298-307 (1993).

5. D. A. Ratcliffe, Journal of Applied Ecology 7, 67-+ (1970).

6. C. D. Sayer et al., Environ. Sci. Technol. 40, 5269-5275 (2006).

7. J. L. Oaks et al., Nature 427, 630-633 (2004).

8. J. P. Desforges et al., Science 361, 1373-1376 (2018).

9. P. P. Egeghy et al., Sci. Total Environ. 414, 159-166 (2012).

10. R. Judson et al., Environ. Health Perspect. 117, 685-695 (2009).

11. S. Strempel, M. Scheringer, C. A. Ng, K. Hungerbuhler, Environ. Sci. Technol. 46, 5680-5687 (2012).

12. L. Posthuma, J. van Gils, M. C. Zijp, D. van de Meent, D. de Zwart, Environ. Toxicol. Chem. 38, 905-917 (2019).

13. T. J. Thrupp et al., Sci. Total Environ. 619, 1482-1492 (2018).

14. C. G. Daughton, Sci. Total Environ. 466, 315-325 (2014).

15. A. C. Johnson et al., Sci. Total Environ. 599-600, 1372-1381 (2017).

16. A. C. Johnson et al., Environ. Toxicol. Chem. 37, 1115-1121 (2018).

17. V. D. J. Keller, R. J. Williams, C. Lofthouse, A. C. Johnson, Environ. Toxicol. Chem. 33, 447-452 (2014).

18. D. Bunke et al., Environ. Sci Eur. 31, 17 (2019).

19. K. L. Thorpe et al., Environ. Sci. Technol. 37, 1142-1149 (2003). 
20. J. P. Sumpter, A. C. Johnson, Environ. Sci. Technol. 39, 4321-4332 (2005).

21. S. L. Waaijers et al., Sci. Total Environ. 463, 1042-1048 (2013).

22. B. A. Woodcock et al., Nat. Commun. 7, 8 (2016).

23. cefic, "Facts and figures of the European chemical industry," (The European Chemical Industry Council, Belgium, 2018).

24. M. Rigby et al., Nature 569, 546-+ (2019).

25. P. Wang et al., Environ. Pollut. 218, 1234-1244 (2016).

26. J. Fick et al., Environ. Toxicol. Chem. 28, 2522-2527 (2009).

27. H. Y. Zhao, R. Percival, Transnatl. Environ. Law 6, 531-549 (2017).

28. S. H. Guo, J. Q. Lu, J. Clean Prod. 212, 1054-1061 (2019).

29. T. Hong, N. N. Yu, Z. G. Mao, J. Clean Prod. 231, 649-659 (2019).

30. G. Q. Li, Q. He, S. Shao, J. H. Cao, J. Environ. Manage. 206, 1296-1307 (2018).

31. S. B. Kedzior, J. Environ. Dev. 26, 272-296 (2017).

32. E. Commission. (European Commission, Brussels, 2019), vol. 2019, pp. Commission web page describing the REACH regulation.

33. E. L. Schymanski et al., Anal. Bioanal. Chem. 407, 6237-6255 (2015).

34. B. W. Du et al., Environ. Sci.-Process Impacts 19, 1185-1196 (2017).

35. J. Hollender, E. L. Schymanski, H. P. Singer, P. L. Ferguson, Environ. Sci. Technol. 51, 1150511512 (2017).

36. M. C. Campos-Manas, I. Ferrer, E. M. Thurman, J. A. S. Perez, A. Aguera, Sci. Total Environ. 664, 874-884 (2019).

37. N. A. McGrath, M. Brichacek, J. T. Njardarson, J. Chem. Educ. 87, 1348-1349 (2010).

38. A. C. Johnson et al., Environmental Toxicology Chemistry. 38, 1820-1832 (2019).

39. M. Gardner et al., Sci. Total Environ. 456, 359-369 (2013).

40. Zhang Q H et al., Environ. Int. 92-93: , 11-22. (2016).

41. M. Bourgin et al., Water Res. 129, 486-498 (2018).

42. UNEP/SAICM, "Strategic Approach to International Chemicals Management. Chemicals in products: The need for information. An emergency policy issue that needs global cooperation.," (2011).

43. G. T. Ankley et al., Environ. Toxicol. Chem. 29, 730-741 (2010).

44. G. T. Ankley et al., Aquat. Toxicol. 92, 168-178 (2009).

45. A. C. Johnson, Y. H. Chen, Sci. Total Environ. 589, 89-96 (2017).

46. M. Yamamuro et al., Science 366, 620-623 (2019).

47. M. Hanson, L. Baxter, J. Anderson, K. Solomon, R. Brain, Sci. Total Environ. 685, 1221-1239 (2019).

48. M. L. Hanson et al., Sci. Total Environ. 578, 228-235 (2017).

49. E. Loken, A. Gelman, Science 355, 584-585 (2017).

50. C. A. Mebane et al., Integrated Environmental Assessment and Management 15, 320-344 (2019).

51. C. A. Harris et al., Environ. Sci. Technol. 48, 3100-3111 (2014).

52. D. A. Notter, D. M. Mitrano, B. Nowack, Environ. Toxicol. Chem. 33, 2733-2739 (2014).

53. E. Mihaich et al., Environ. Toxicol. Chem. 31, 2525-2535 (2012).

54. A. C. Johnson, J. P. Sumpter, Environ. Toxicol. Chem. 35, 1609-1616 (2016).

55. ECHA, "The use of alternatives to testing on animals for the REACH Regulation," (European Chemicals Agency, Helsinki, Finland, 2017).

56. L. Weltje, J. P. Sumpter, Environ. Sci. Technol. 51, 11520-11521 (2017).

57. F. Sanchez-Bayo, K. A. G. Wyckhuys, Biol. Conserv. 232, 8-27 (2019).

58. C. A. Hallmann et al., PLoS One 12, 21 (2017).

59. M. O. Gessner, A. Tlili, Freshw. Biol. 61, 1991-2001 (2016). 


\section{Acknowledgments}

The authors are grateful to Monika Jürgens (CEH) for technical support and to Michael Funk and his team at Science for editorial assistance. Funding: Johnson and Sumpter are grateful to NERC for grant NE/S000100/1 supporting the ChemPop project. Author contributions: The form and structure of the paper was conceived by Johnson. The writing of the different sections were then divided between each of the authors. Competing interests: Johnson and Sumpter are currently members of the Defra (UK) Hazardous Substances Advisory Committee, no other competing interests are known 